\title{
O PAPEL DO (A) ENFERMEIRO (A) DO TRABALHO NA REINSERÇÃO SOCIAL DA PESSOA COM DEFICIENCIA
}

\author{
* Terezinha Aparecida Neves \\ * Marlucia Nunes Comaru \\ *** Adelia Ono Tonaki \\ Eneida Stigliano
}

$\operatorname{ReBEn} / 02$

NEVES, T. A. e Colaboradores - O Papel do(a) Enfermeiro(a) do Trabalho na Reinserção Social da Pessoa com Deficiência. Rev. Bras. Enf.: RS, 35: 192-199, 1982.

\section{INTRODUÇÃO}

Uma das questōes mais atuais em relação a Direitos Humanos é a questão dos Direitos das Pessoas Deficientes. Nesse sentido, foi resolvido na 34 a . Sessão da ONU, em 1979, que 1981 seria o Ano Internacional das Pessoas Deficientes, recomendando que fossem realizadas uma série de açōes que venham promover a "concretização dos direitos das pessoas deficientes, notadamente na participação da vida social em toda a sua plenitude nas mesmas bases e em idênticas condiçōes dos demais cidadâos". (1).

E a própria ONU que reconhece como pessoa deficiente aquela "que por si mesma é incapaz de assegurar, total ou parcialmente, as necessidades de uma vida individual ou social normal, em decorrência de uma deficiência, congênita ou não, em suas capacidades físicas ou mentais". (1).

Uma das justificativas da ONU para uma tomada de posição de tal natureza é a estimativa de que cerca de 450 milhōes de pessoas no mundo apresentam alguma forma de deficiência. No Brasil considera-se este número como aproximadamente 12 milhōes ou seja, em cada 10 brasileiros 1 é portador de algum tipo de deficiência. A esses dados, estatísticas projetadas esclarecem que devem ser acrescentados anualmente mais 3 milhōes de novos deficientes.

Esses indivíduos encontram-se na sua maioria, marginalizados, quer seja em asilos, sanatórios, hospitais, creches e instituiçōes assistenciais (cuja assistência é discutível), nos quartos de fundo das casas de família e uns poucos confinados a seus lares. Esta marginalização se deve não só às condiçōes funcionais impostas pela deficiência, mas ainda a barreiras físicas impostas pelas condiçōes arquitetônicas das cidades, barreiras pessoais como analfabetismo e inabilidade, prática para resolver seus problemas e barreiras sociais ditadas pelo preconceito e discriminação da população em geral.

* Enfermeira do Trabalho - chefe de seção do Serviço de Enfermagem da Divisão de Reabilitação Profissional de Vergueiro - Hospital das Clínicas - FM USP.

* Enfermeira - Diretora do Serviço de Enfermagem - idem

** Enfermeira - chefe de seção - idem

*** * Enfermeira - idem 
NEVES, T. A. e Colaboradores - O Papel do(a) Enferıneiro(a) do Trabalho na Reinserção Social da Pessoa com Deficiência. Rev. Bras. Enf.:RS, 35:192-199, 1982.

Lutar contra esses problemas não é empreendimento fácil, nem de baixo custo, mas tentamos encará-los como um desafio; atuemos dentro daquilo que estiver ao nosso alcance, ao alcance das enfernneiras. Se aceitarmos esse desafio poderemos ajudar a integração ou reintegração de muitos indivíduos deficientes na sociedade, mediante o desempenho de papéis sociais mais adequados à sua potencialidade e condições, ampliando a partir daí seu universo de participação como ser humano e cidadầo. É nesse contexto que se insere o enfermeiro do trabalho, que não temos dúvida, será mais um elemento positivo para contribuir na consecução dos objetivos do A.I.P.D., dentro dos quais destacamos: a colaboração no ajustamento social das pessoas defícientes, a promoção de esforços para proporcionar oportunidade de emprego apropriado, a educação e infornação do público quanto aos seus direitos de participar e contribuir para diversos aspectos da vida econômica, social e política e a promoção de medidas concretas de prevenção de incapacidades. Tais objetivos, somados a outros irão certamente ajudar a atingir a meta de Participação Plena e Igualdades.

É preciso, de antemão reconhecer que as pessoas com deficiência, além das necessidades básicas por todos nós conhecidas têm uma necessidade básica específica - a de se beneficiar de serviços de Habilitação/Reabilitação, sem os quais não conseguiriam "sair das situações típicas de dependência ou inadequada atuação por seus próprios meios". (3). Tais serviços exigem o trabalho integrado do grupo de profissionais que abordam a pessoa com deficiência sob o ponto de vista rigorosamente global e abrangente, procurando ajudá-la no ajustamento físico, psico-social e à vida de trabalho. A enfermeira vem pouco a pouco garantindo o seu lugar nessa equipe, porque identificou lacunas nesse tipo de assistência que à ela caberia preencher.

Uma breve menção de Horta vem demonstrar a abrangência do papel da enfermeira na estória de vida de todos os "seres humanos, em qualquer fase do seu ciclo vital e do ciclo saúdeenfernnidade". De passagem, poderíamos mencionar a atuação da enfernneira nos aspectos preventivos e de promoção da saúde, integrado nas fases preventivas, curativas e de reabilitação. Enfocando a fase curativa podemos constatar a participação obrigatória da enfernneira no processo evohutivo de doenças crônicas degenerativas, na atenção em unidades de emergência e em U.T.I e nas demais modalidades. A enfermeira acompanha o paciente e sua família nas fases mais críticas, do nascimento a morte, passando por episódios de instalação brusca ou progressiva das deficiências. É inquestionável sua responsabilidade para aplicação correta e adequada das medidas terapêuticas e preventivas, sem descuidar do seu papel expressivo. Conhecer o paciente e perceber o que é mellor para ele, fazê-lo participar de cada etapa de sua assistência facilitará sem dúvida o seu retorno mais rápido à família. $\mathrm{O}$ ideal que deve ser perseguido incessantemente por nós é que cada paciente possa, por ocasião de alta, estar o mais próximo possível do seu padrão, em condições de retornar ao seu estilo de vida anterior. Mas, sabemos que há situações irreversíveis, caracterizadas pela instalação de deficiências que comprometem o equilíbrio familiar em seus aspectos globais. E a enfermeira se pergunta: Qual será o futuro destes pacientes? Como sobreviverão a tantas difículdades? Dada a extensão e gravidade do problema o paciente necessitará dos recursos especiais de Centro de Habilitação/Reabilitação, para o qual deverá ser encaminhado, desde que a comunidade disponha de tal recurso. Nesses centros o paciente, agora cliente, mais participante e esclarecido quanto a seus problemas atuais e futuros, poderá encontrar novamente a enfermeira para ajudá-lo, integrado a outros profissionais da equipe.

Nessa equipe, a enfernneira irá contribuir decisivamente no processo de reintegração, mediante formas específicas de trabatho, e direcionado para cada cliente em particular, ajudando-o a assumir as atividades do auto-cuidado como cuidado corporal, vestuário, cuidado com aparência pessoal, alimentação, eliminação, desempenho de atividades do lar e outros. Essas atividades são fundamentadas nos aspectos de Educação que levam o cliente a promover e proteger sua saúde, através de um "methor conhecimento de seu próprio corpo, suas reaçōes, susceptibilidades e, a partir daí, assumir com fundamentaçạao o auto-cuidado. São componentes dessa atividade educativa: conhecimento do próprio corpo, educação sexual, saneamento básico, prevenção de doenças e complicações, prevenção de acidentes no lar e no trabalho, orientação e utilização de recursos da comunidade, orientação e reforço quanto a necessidade de controle médico periódico para a manutenção do nível funcional ótimo, ainda que portador de deficiência". (2).

Decorrente da evolução global advinda do seu próprio esforço e colaboração da fam ília e do traballho harmônico da equipe multi-profissional o cliente irá se tornando progressivamente mais 
NEVES, T. A. e Colaboradores - O Papel do(a) Enfermeiro(a) do Trabalho na Reinserção Social da Pessoa com Deficiência. Rev. Bras. Enf.:RS, 35: 192-199, 1982.

confiante e independente no seu cuidado pessoal, se permitindo até formular planos para uma vida mais plena no futuro. Irá descobrir novas formas de viver, de atender as suas necessidades básicas. $\mathrm{E}$ dentre estas, segurança financeira e auto-realização são as necessidades que o impulsionam para a vida de trabalho, competindo com o melhor de si no mercado. A passagem da dependência para independência está registrada quando ele entra neste contexto. $\hat{E}$ evidente que não podemos deixar de registrar com os incontáveis casos de pessoas com deficiências que por falta de recursos adequados não têm a sorte de se beneficiar de programas especiais, sendo encaminhados, ainda assim, para o mercado de traballho. Cabe aqui ressaltar, que a atuação da enfermeira do trabalho junto a eles será de fundamental importância, nos aspectos que se seguem.

\section{ATUAÇĀO DA ENFERMEIRA DO TRABALHO JUNTO AO TRABALHADOR COM DEFICIÊNCIA}

Graças ao enfoque que as organizaçōes internacionais e nacionais estão dando ao AIPD, estamos seguros de que, em futuro bem próximo, conseqüêntes às disposiçōes dos diversos grupos da sociedade, haverá um grande fluxo de pessoas capacitadas para trabalhar, embora portadoras de deficiência.

E nesse estágio, que se inicia a participação da enfermeira do trabalho no processo de integração/reintegração social das pessoas com deficiência. Ela poderá ser elemento mais participante na medida em que ajude a esclarecer o público sobre o potencial desses trabalhadores, contribuindo para remover barreiras e preconceitos, abrindo estradas por onde hão de passar muitas pessoas que, embora por vezes nos choquem visualmente, são capazes de alcançar com seu trabalho e seu talento, o sustento próprio e de sua faḿlia. E isto que os ajuda a sentirem-se cidadãos comuns, gente como nós, com os direitos e deveres inerentes a todo cidadão, ainda que com problemas especiais.

A enfermeira do trabalho, dentro das suas funçōes tradicionais deverá estar atenta para alguns enfoques especiais que passaremos a enumerar:

1 - No assessoramento à equipe de saúde:

- junto à equipe:

- conscientizar seus componentes para que vejam a pessoa portadora de defíciência como alguém capaz de produzir, apesar de ser portador de uma seqüela;

- trazer à equipe, dados sobre o desempenho das pessoas com deficiência que tenham obtido sucesso no seu papel de produtor de bens;

- despertar na equipe a necessidade da continuidade dos exames periódicos específicos à prevenção de maiores agravos à saúde face a seu quadro clínico desencadeante da deficiência e função exercida.

- junto ao candidato:

- realizar entrevista de enfermagem com objetivo de levantar suas reais condições para o atendimento de suas necessidades básicas, confrontando posteriormente esses dados com as condiçōes físicas do local de trabalho: (existência de degraus $\mathbf{x}$ cliente em cad. de rodas).

- orientar preparo aos exames complementares ou específicos e desenvolver programa de orientação, se necessário;

2 - Na identificação dos agentes de desequilibrio homem/ambiente:

A enfermeira deve estar atenta às barreiras do meio ambiente, que interferem no desempenho das atividades de todos os trabalhadores e que poderão ser muito mais significativas para as pessoas que portam deficiências.

Após a identificação dos problemas a enfermeira deve tentar algumas facilitações, quer seja junto a equipe, quer seja junto ao trabalhador. 
NEVES, T. A. e Colaboradores - O Papel do(a) Enfermeiro(a) do Trabalho na Reinserção Social da Pessoa com Deficiência. Rev. Bras. Enf.: RS, 35: 192-199, 1982.

Como exemplos de problemas e das facilitações podemos citar:

- trabalhadores que necessitam de maior hidratação e que usam o sanitário com mais freqüência devem ter facilidades de acesso aos bebedouros e sanitários, preferencialmente;

- pessoas portadoras de visão sub-normal devem trabalhar sob condições especiais de iluminação para o seu comprometimento: ex: reflexão de raios luminosos $\mathrm{x}$ campo da telelupa.

- pessoas que usam cadeiras de rodas, próteses, órteses, muletas e bengalas, devem ter acesso aos diferentes locais no ambiente de trabalho. Para tanto muitas vezes se faz necessário of erecer algumas facilitações como por exemplo a colocação de uma cadeira comum no interior do sanitário para permitir a transferência de pessoas paraplégicas; melhor posicionamento de móveis para ampliação do espaço; pequenas rampas onde existem degraus;

- pessoas portadoras de problemas de coluna ou de problemas quanto à mecânica corporal devem permanecer acomodadas em bancos ou assentos especiais a seu tipo de comprometimento (mais altos ou mais baixos), ou ainda que exigem algum acima extra ou adaptação.

- em casos de refeitórios, as mesas quando muito próximas umas das outras, dificultam a aproximação de pessoas com cadeiras de rodas ou órteses. Nesses casos deve-se estudar a possibilidade de distanciar algumas das mesas ou estabelecer que as mesas das extremidades possam ser liberadas a eles. As pessoas portadoras de deficiência visual devem ser bem orientadas e, em alguns casos auxiliadas nos primeiros dias para que possam se orientar no ambiente e tornar-se independente.

Esses são apenas alguns exemplos de problemas comuns às pessoas com deficiência e algumas facilitações que podem ser feitas. Os meios pelos quais se podem processar as facilitações são os mais diversos possíveis e dependem muito da criatividade, esforço e boa vontade por parte daqueles que trabalham na área da saúde ocupacional e também por parte do trabalhador, deve colaborar dando informações objetivas. Deve-se ressaltar a importância de se conhecer não só o potencial como as limitações do indivíduo e suas implicações durante o desempenho de atividades.

3 - Na educação:

E através do processo educativo que a enfermeira contribuirá para maior compreensão das pessoas sobre seu corpo, seus limites de segurança e importância da saúde. A consideração da saúde como o bem maior do indivíduo garantirá uma atuação mais consciente e cuidadosa para se precaver dos agravos que a ela podem suceder num ambiente de trabalho não salu tar. Estamos falando de prevenção.

\section{E como funciona o corpo de uma pessoa com deficiência?}

Esta é uma das explorações ou explanações que se deve fazer dentro do processo educativo quando trabalhamos com pessoas portadoras de deficiência. $\mathrm{O}$ enfermeiro (a) deve saber orientar sobre as diferentes deficiências, em seus aspectos específicos como por exemplo: implicações da longa permanência numa mesma posição (sentado ou em pé) no aparecimento ou agravamento de problemas renais, vesicais, articulares ou de pelo em paraplégico ou amputados; o agravamento dos quadros de cegueira em pessoas portadoras de visão sub-normal quando trabalham em locais mal iluminados; possíveis complicações de pele nos portadores de próteses de membros devido a longas caminhadas.

Note-se que para se estabelecer um programa de educação, há necessidade de distanciar, por algum tempo, o indivíduo de seu serviço e para tal é preciso que os setores administrativos e o de enfermagem mantenham um bom relacionamento. A educação em grupos além de outras contribuições, of erece à enfermeira oportunidade de atuar na quebra de barreiras atitudinais, através de esclarecimento objetivo sobre as reais condições funcio- 
NEVES, T. A. e Colaboradores - O Papel do(a) Enfermeiro(a) do Trabalho na Reinserção Social da Pessoa com Deficiência. Rev. Bras. Enf.; RS, 35: 192-199, 1982.

nais de indivíduos portadores de diferentes tipos de deficiências.

4 - $\mathrm{Na}$ análise das doenças ocupacionais e acidentes de trabalho:

Através de observações contínuas e sistemáticas, procura-se identificar as causas das doenças ocupacionais e acidentes de trabalho, com a finalidade de diminuir sua incidência, atuando tanto em relação ao homem como também ao meio ambiente.

Dentro dessas análises abre-se novo campo de pesquisa para a enfermagem: o estudo da incidência entre acidentes de trabalho e doenças ocupacionais na população de trabalhadores com deficiência.

O que tem sido observado no nosso meio, é uma automática rejeição, da parte das empresas, com relação ao candidato a trabalho que apresenta uma determinada deficiência, porque a existência desta é erroneamente associada ao absenteísmo no trabalho e a licença médica. Será este conceito verdadeiro? O julgamento precipitado e não fundamentado contribui portanto para que as pessoas com deficiência tenham dificuldade de acesso ao trabalho competitivo, sendo como conseqüência impedidos de contribuir para o progresso social.

5 - Na proposição de alteração e reforço das medidas de prevenção que levem ao desempenho mais seguro e adequado das funções:

- o incentivo ao uso de equipamentos especiais de segurança é responsabilidade da Comissão Interna de Prevenção de Acidentes - CIPA - e a enfermeira que a integra deve reforçar a necessidade de seu uso através de orientações específicas voltadas para a prevenção. Com referência ao uso de máscaras, luvas e gorros nas indústrias farmacêuticas, que muitos entendem como "um modo de não contaminar o material" o enfoque precisa ser alterado para o significado maior de "não se contaminar"; o uso de fones ou tampões nos ouvidos quando o trabalhador é permanentemente exposto aos ruídos excessivos; uso sistemático das máscaras ou óculos nas atividades em que o indivíduo está sujeito a sofrer lesões na face ou no globo ocular (uso de esmerilho).

6 - No reconhecimento de situações de risco e inadaptação do homem à função:

- além do que já foi referido no item 2, temos a acrescentar ainda, que deve-se analisar as condiçōes de atuação do trabalhador a fim de identificar possíveis inadaptaçōes do homem à função. Sabe-se que a inadaptação da pessoa a seu trabalho é fator de risco, aumentando a possibilidade de erros, acidentes e stress emocional e físico. Exemplificando temos o caso de pessoas cardíacas que trabalham em locais com altas temperaturas ou sob tensão constante.

7 - Na participação das CIPAS:

- uma das contribuições mais efetivas da enfermeira do trabalho, junto às CIPAS, é sua atuação preventiva nos aspectos da deteç̧ão de condiçōes inseguras e dos atos inseguros. Esses dados chegam naturalmente à enfermeira na medida em que o trabalhador a veja como um elemento preocupado não apenas com a produtividade industrial, mas também e principalmente com seu desempenho dentro das normas de segurança e equilíbrio entre o homem (bio-psico-social) e o ambiente (físico e material).

Deve-se atentar às condiçōes físicas das pessoas portadoras de deficiência e as condições de ambiente de trabalho, dada as limitações em termos de locomoção, o que acarreta uma maior probabilidade de acidentes. Pessoas com deficiências visuais por exemplo que trabalham em locais com grande número de maquinário e têm pouco espaço para utilização da bengala correm riscos de acidentes.

Deve-se dar ênfase a atuação da CIPA também nesses casos, devendo a enfermeira como elemento integrante dessa equipe e também da equipe de saúde atentar para os aspectos ainda inexplorados e que podem contribuir parą a ocorrência de agravos à saúde e que resultam, muitas vezes, na instalação de deficiência. 
NEVES, T. A. e Colaboradores - O Papel do(a) Enfermeiro(a) do Trabalho na Reinserção Social da Pessoa com Deficiência. Rev. Bras. Enf.: RS, 35:192-199, 1982.

8 - No atendimento a emergências:

- a enfermeira procurará atuar com presteza, segurança e adequacidade, de modo a impedir agravos mais sérios a saúde do trabalhador.

9 - Nas anotações:

- no registro criterioso e preciso das ocorrências a enfermeira pode auxiliar na incrementação dos dados estatísticos para futuros traballos de pesquisa que venham demonstrar riscos ainda não identificados.

Nesses, a observação atenta e capacidade criativa poderão levar a soluções viáveis em favor da segurança do trabalhador com deficiência.

\section{CONCLUSĀO}

Procuramos enfocar a participação da enfermeira do trabalho na reinserção do indivíduo portador de deficiência; sua contribuição é essencial como elemento de apoio e de complementação das atividades de atenção global às necessidades básicas da pessoa com deficiência, atendida anteriormente em Serviços de Habilitação/Reabilitação que lhes assegurem uma adequada articulação entre o seu trabalho, sua capacidade física, suas potencialidades e o ambiente social.

Se o propósito dos serviços de saúde é a obtenção do equilíbrio entre o homem e seu meio ambiente, a enfermeira como elemento integrante e participante dessa equipe, deve estar atenta para planejar suas ações de modo a contribuir objetivamente para o alcance desse propósito.

Sendo a enfermeira um profissional que, por características de desempenho acompanha o ser humano no seu ciclo vital, sobre elas recaem oportunidades infinitas de dar e receber, contribuindo assim para a elevação ou manutenção do paciente ou cliente na sua condição de ser humano, de gente com direitos inalienáveis e potencial a ser explorado de modo a alcançar seu ápice através do desempenho satisfatório.

\section{CONSIDERAÇŌES}

1. como direito das pessoas portadoras de deficiências, a participação plena e igualdade:

- que u m dos objetivos da carta de 1980, aprovada na Assembléia Internacional de Reabilitação em Winninpeg é "executar todas as medidas necessárias para oferecer a maior integração e participação possível das pessoas deficientes na vida da comunidade"; e

- também difundir informações sobre as pessoas deficientes e suas capacidades; a deficiência e sua prevenção e tratamento, com a finalidade de aumentar os conhecimentos e conscientizar o público destes problemas e de sua importância para cada sociedade;

2. que o trabalho é a complementação do atendimento iniciado na reabilitação global;

3. o desconhecimento das enfermeiras que atuam em outras áreas de assistência à saúde, a respeito das necessidades dos indivíduos portadores de deficiência;

4. que uma pessoa com deficiência que tenta disputar uma vaga no mercado de trabalho, na maioria das vezes, é possuidora de condições para executar a função;

5. que o homem deve ser visto como participante de uma economia e não apenas como agente de produção;

6. que as dificuldades encontradas pelo grupo em conseguir bibliografia referente às atividades da enfermeira do trabalho junto as pessoas portadoras de deficiências;

7. que algumas pessoas portadoras de deficiência embora reabilitadas podem apresentar intercorrências específicas na área da saúde. 


\section{RECOMENDAÇÕES}

1. que as enfermeiras, através da assistência de enfermagem global e planejada atendam de modo a: a) prevenir a instalação de deficiência; b) minimizar os efeitos da deficiência;c) facilitar a integração ou reintegração do indivíduo portador de deficiência ao seu meio social em condiçōes de participação plena:

- que as enfermeiras, por meio de contatos com a comunidade, desempenhem seu papel de orientadora e educadora contribuindo, para a quebra de barreiras atitudinais para com as pessoas portadoras de deficiência;

2. que as enfermeiras do trabalho atuem de forma a manter o nível funcional ótimo do trabalhador com deficiência, de modo a facilitar o desempenho de seus papéis de produtor de bens;

3. que as enfermeiras procurem participar mais ativamente de encontros específicos, visando alcançar maior e melhor troca de experiências;

- que as enfermeiras que trabalhem no campo da habilitação/reabilitação procurem elaborar trabalhos ou cursos para divulgação de suas experiências; através do trabalho;

4. que a enfermeira do trabalho seja um elemento de facilitação na sua reinserção social

5. que a enfermeira do trabalho atue como agente de prevenção e de promoção da saúde procurando adequar o ambiente ao homem e não o homem ao ambiente;

6. que as enfermeiras do trabalho divulguem suas experiências, elaborem estudos a respeito da atuação das pessoas com deficiência no seu papel de trabalhador;

7. que a enfermeira de trabalho esteja atenta as suas peculiaridades e programem um atendimento de caráter preventivo, visando a manutenção do seu nível funcional ótimo e desempenho satisfatório.

\section{BIBLIOGRAFIA}

(1) ASSEMBLÉIA DE REABILITAÇĀO Internacional - Carta de 1980, Winninpeg, 22-27, junho, 1980.

(2) COMARU, M.N. Contribuição do (a) enfermeiro (a) nos aspectos de ajustamento social das pessoas com deficiência - Palestra proferida na III Jornada de Enfermagem - Alagoas, Maio, 1981.

(3) COMISSÃO ESTADUAL de Apoio e Estímulo ao Desenvolvimento do Ano Internacional das Pessoas Deficientes - Relatório - São Paulo, 1981.

(4) Declaração dos Direitos das Pessoas Deficientes - ONU, 09/12/75.

(5) PEREIRA, D.W. - Reabilitação Profissional do Acidentado - Rev. Brasileira Saúde Ocupacional, S. Paulo, 7 (28) : 73-6, 1979.

(6) RUY, A.S. - Controle da Eficiência do Trabalho, Coleção da Engenharia de Produção e Administração Industrial - São Paulo, 1967 
NEVES, T. A. e Colaboradores - O Papel do(a) Enfermeiro(a) do Trabalho na Reinserção Social da Pessoa com Deficiência. Rev. Bras. Enf.: RS, 35: 192-199, 1982.

(7) SASSAK, R.K. - Atividade da Vida Diária e Sucesso Profissional do Reabilitado, S. Paulo, agosto, 1968.

(8) SILVA, O.M. - Marginalidade - Apostila elaborada para treinamento de pessoal em serviço da D. R.P.U. - FM - USP, janeiro, 1970.

AVALIAÇĀO e Controle nos centros de reabilitação - Palestra proferida no II Curso de Especialização em conselhamento de reabilitação, 1977. 